Article

\title{
Social Capital and Running: A Network Social Capital Perspective
}

\author{
Shang-Chun Ma ${ }^{1, *}$ and Kyriaki Kaplanidou ${ }^{2}$ \\ 1 Institute of Physical Education, Health, \& Leisure Studies, College of Management, National Cheng Kung \\ University, Tainan 70101, Taiwan \\ 2 Department of Sport Management, University of Florida, Gainesville, FL 32611, USA; \\ kkaplanidou@hhp.ufl.edu \\ * Correspondence: 10102009@gs.ncku.edu.tw
}

Citation: Ma, S.-C.; Kaplanidou, K. Social Capital and Running: A Network Social Capital Perspective. Sustainability 2021, 13, 12398. https:// doi.org/10.3390/su132212398

Academic Editors:

Adela García-Aracil and

Giuliana Birindelli

Received: 9 October 2021

Accepted: 4 November 2021

Published: 10 November 2021

Publisher's Note: MDPI stays neutral with regard to jurisdictional claims in published maps and institutional affiliations.

Copyright: (c) 2021 by the authors. Licensee MDPI, Basel, Switzerland. This article is an open access article distributed under the terms and conditions of the Creative Commons Attribution (CC BY) license (https:// creativecommons.org/licenses/by/ $4.0 /)$.

\begin{abstract}
This study examines the measurement of position generators as a proxy of network social capital (NSC) and its influence on the extensity and upper reachability of social capital and sport/running participation. An analysis of 373 runners shows that running exercise participants rely on diverse relations to access and increase their social capital levels; stronger ties with the accessed occupations via running activities can help reach people with higher occupational prestige; access to more intermediate class occupations is significantly positively associated with upper reachability, whereas access to more working class occupations is significantly negatively associated with upper reachability; those who are older and have strong ties with people in accessed occupations known via running activities have higher levels of sport/running participation. We provide evidence for the application of NSC theory in sport to better understand how social networks operate by accessing extensity and upper reachability of social capital and how NSC influences sport (running) participation.
\end{abstract}

Keywords: network social capital (NSC); position generator; running; sport participation; social class

\section{Introduction}

Sport participation is strategically promoted by policy makers because of its impacts on health, social development, economic development [1], and overall quality of life (QoL) [2]. Running is a popular form of exercise and sport participation [3]. One important social impact of sport participation is the development of social capital [4], which can increase social connectedness, a sense of belonging [5], and trust [6].

The value of social capital has been recognized as being key to sport participation development and has attracted sport scholars' attention. For example, Downward et al. [2] found an insignificant relationship between social capital and sport participation, although the results could be contested, as social capital (i.e., perception of trust) and sport participation (i.e., total minutes of sports activity per week in the past 4 weeks) were measured with only a single question each. Kumar et al. [1] examined the impact of sport delivery systems aimed at promoting sports participation in end users and found significant differences between facility types on social and commercial objectives, denoting that the divergence has little impact on social capital as a result of user participation. Zhou and Kaplanidou [7] examined runners as event participants and found that social capital could influence their healthy lifestyle decisions. Mastromartino et al. [8] examined factors constituting a sense of membership in a sport fan community and their impact on the creation and maintenance of social capital and found that a sense of membership can contribute to bridging and bonding social capital. Despite increasing evidence of associations between sport participation related constructs and social capital, it is less clear through which mechanisms network social capital (NSC) influences sport participation. NSC assumed that the resources are determined by someone's position in society, and social networks/ relational ties allow 
these resources to flow according to which actions are taken to obtain the resources [9]. In comparison with NSC, social capital has been studied in general by referring to an emphasis on networks, norms [10], and, in particular, social trust [10,11]. Specifically, there are multiple frameworks in the literature, and the deficiency is also reflected in the use of three main theories by Bourdieu [12], Coleman [13], and Putnam [10], which influenced the direction of studies to not focus on NSC.

Social capital is widely defined as the resources embedded in social networks (i.e., relational ties), which are available to members of social groups [14], but it has rarely been examined with this definition in the sport literature. Widdop et al. [15] and Legh-Jone and Moore [16] used the NSC perspective to explore associations between sport participation and social capital. However, inadequate measures adopted in their work yielded unclear findings and thus missed the opportunity to fully understand how the NSC perspective could be useful in sport.

Running, as the participatory sport within the context of this study, is one of the most popular sports in Taiwan. According to national annual surveys between 2017 and 2020 ( $N=$ around 25,000) by the Sports Administration, Ministry of Education in Taiwan [17], around $33 \%$ of respondents exercise regularly (3 times a week, 30 min per time, and moderate-to-vigorous intensity) and around 10\% expressed that running is their favorite way of participating in sport. Furthermore, a national survey $(N=6185)$ by Running Biji [18] revealed an outlook of Taiwan runners in 2020. The respondents were $64 \%$ male and $36 \%$ female; $30 \%$ of males run $21-40 \mathrm{~km}, 24 \%$ run $11-20 \mathrm{~km}$, and $18 \%$ run $41-60 \mathrm{~km}$ weekly, while $32 \%$ of females run less than $10 \mathrm{~km}$, around $30 \%$ run $11-20 \mathrm{~km}$, around $25 \%$ run $21-40 \mathrm{~km}$, and 10\% run 41-60 km weekly; track and field stadiums are the top choice of place for running, streets and sidewalks come in second, and riversides are third.

To fill the research gaps, this study aimed to build upon the NSC perspective [19] and the measurement of people's position in society, termed as position generators [20,21] in the participatory sport context (i.e., running). Thus, we aimed to examine how social networks exert effects on accessing volume (i.e., the number of occupations they can access in a network) and upper reachability (i.e., the highest position they can access in a network) of social capital, and the influences of NSC on sport participation in the participatory sport context.

\section{Literature Review}

\subsection{Social Capital}

Three scholars are widely mentioned when defining social capital: Bourdieu [22], Coleman [13], and Putnam [10]. While the full term of social capital has been addressed and widely discussed, its definitions are seldom seen. According to Bourdieu, "capital is a form of power, the capacity individuals and groups might have to impact upon, change or control situations" [23] (p. 168), while social capital is "the aggregate of the actual or potential resources which are linked to the possession of a durable network of more or less institutionalized relationships of mutual acquaintance and recognition" [12] (p. 248). This definition focuses on social class, inequality, and competing power among different actors, highlighting the individual pursuit of interests [24]. Coleman [13] (p. 98) defined social capital by its function, saying that "it is not a single entity but a variety of different entities, with two elements in common: they all consist of some aspect of social structures, and they facilitate certain actions of actors-whether person or corporate actors-within the structure." This definition places further emphasis on the interests of the collective. Putnam [10] (p. 66) defined social capital as "the features of social organization such as networks, norms and social trust that facilitate coordination and cooperation for mutual benefits." This definition extends Coleman's [13] by focusing more on the individual level compared to the collective traits of broader populations [25]. Focusing on the individual level within social capital has received wider attention in political and socioeconomic contexts [25] and sport and leisure studies [26]. Based on the NSC theory, Lin [20] (p. 24) took a different approach from Putnam [27], defining social capital as "resources embedded 
in social networks that can be mobilized when an actor wishes to increase the likelihood of success in a purposive action." This definition puts the person in control of mobilizing and accessing resources to achieve a purpose. Similarly, as Lee, Cornwell, and Babiak [28] found, the more exposure a person has to community sports, the larger the positive influence on their social capital perceptions, health literacy, and collective identities. Given that the context of this study is in a collective culture, social capital can be critical in networking. While definitions of social capital vary due to disciplinary background [29], this study drew theoretical assumptions from the perspective of NSC [21] as it best fit the research purpose.

\subsection{Network Social Capital (NSC) Theory}

NSC conceptually refers to social network resources [12]. According to Lin's [9] and Lin et al.'s [30] proposition, NSC comprises the resources of social networks/accessibility, resources/embeddedness, and their mobilization or use. Specifically, social networks are the relational ties between sets of actors, as well as the pattern or structure emerging from those ties, which are pathways allowing the resources to flow [31]. In contrast, resources are either material or immaterial and are found within the interpersonal relationships and networks. Actions are taken to obtain these resources, either to achieve instrumental (e.g., wealth, power, reputation) or expressive (e.g., physical health, mental health, life satisfaction) returns [9]. Therefore, the ability to access the social resources embedded in social networks can result in better socioeconomic status, where this accessibility is partly determined by one's positions in the hierarchical structure and by one's use of weaker ties [9].

The significance of resources and relations in social capital has attracted scholarly attention to their locations [9]. The network location measurement may comprise several components, such as the strength of the network ties, density, size, closeness (i.e., the distance from oneself (ego) to all others in the network), betweenness (i.e., "the number of times that ego falls along the shortest path between two other actors"), and eigenvector (i.e., "the extent to which ego is connected to nodes, who are themselves high in eigenvector centrality") [32] (p. 31). In contrast, social resources measurement can be specified as either network resources (i.e., the resources embedded in one's ego-networks) or as contact resources (i.e., the resources embedded in the contacts used as helpers in an instrumental action, such as job research) [9]. For example, the results of Lin, Chen, and Fu's [33] examination of the patterns and effects of social relations in Taiwan, the United States, and China indicated that, in the United States, friends and other ties exert stronger effects to gain access to better social capital; in China, kin ties, friends, and other ties have a shared effect on such access, while in Taiwan, there is an overlap of kin ties, friends, and other ties, but not to the same extent as in China.

\subsection{Social Networks}

Past studies [34,35] have noted that an individual's position within the structure may influence the resources available to its members. In addition to an individual's position, social ties are a key element of social capital affecting the accessibility of network resources [9]. Social ties refer to any kind of social relationship between two network members [21]. Within social ties, the willingness of network members (also known as alters) to provide resources to the focal actor under consideration (called the ego) is called "tie strength" [31] (p. 18), where the difference in tie strength may be indicated by different types of ties in the social networks, such as friends or acquaintances [21].

Furthermore, tie strength in a social capital context is also expressed in "strong" and "weak" terms [36]. Strong ties are more reliable, reciprocal, and solid; network members known via this kind of tie show a higher willingness to help, information travels faster, and people can more easily reward each other [21]. Weak ties refer to less close and reliable relationships, through which the function of bridging between networks is expected [37]. However, weak ties allow wider reaches to social resources owned by different others in the social structure [36]. 


\subsection{Measuring Network Social Capital}

NSC can be measured, from an ego network perspective, using three approaches [38]. The first is name generators, which ask respondents to name others (i.e., alters) [38] with whom they are connected. Once the alters have been named, respondents are questioned about each one, including their gender, health-related behaviors, and income, and may be asked whether these alters interact with each other; this is a way to indicate the density of the ego network [39]. Using name generators in surveys tends to capture a person's strong ties [38].

The second approach is position generators whereby respondents are asked to identify anyone they have social ties with who holds a certain social position or occupation [19]. A list of occupations (e.g., the Standard International Occupational Prestige Scale, SIOPS) is provided to the respondents, where each is assigned a prestige score [38]. It is thus possible to measure an individual's social capital in three ways: (1) the extensity of their social ties (i.e., the number of occupations they can access); (2) upper reachability, (i.e., the highest position they can access); and range, (i.e., the difference between the highest and lowest ranked position they can access) [19]. The third way of measuring social capital is resource generators, which provide a fixed list of specific resources. Respondents are asked to use this list to identify which resources they have access to and the tie strength [40]. Resources can be classified into different fields such as prestige and education-related resources and are evaluated for their importance in relation to health or QoL [38]. This measurement has, however, scarcely been used in the social capital research in the sport context.

\subsection{Position Generator Measures: Variables under Study}

The position generator approach was developed by Lin [19]. It was adopted in the current study because it has the advantages of being easy to use, has high response rates and short question times, and is applicable to multiple settings compared to name or resource generators [41]. Using a position generator when measuring social capital can quantify social network resources through five approaches [41]. The number of network resources or the extensity of an individual's social ties is calculated according to the total number of occupations on the position generator lists they can access. This is based on the assumption that the more ties one has via one's social network, the better resources one can access [21]. By referring to the occupational prestige scales, position generator measures can evaluate the standing in society of various occupations [42]. According to Treiman [43], different societies have similar occupational prestige hierarchies, and there is a strong consensus on the existence of this kind of hierarchy across societies. In addition, Lin [44] argued that occupational prestige can be an indication of universally valued resources (wealth, status, power). This indication has been widely used to construct position generator measures since its application by Lin and Dumin [45]. Ganzeboom and Treiman's [42] Standard Occupation Prestige Scale (SIOPS) is the most widely adopted scale and has been used in position generator studies in various countries including the United States [46], Canada [47], and Japan [48].

The second measure is the average occupational prestige of network resources. This value is calculated by dividing the summed prestige scores of the selected occupations by the total number of accessed occupations [49]. Accordingly, a higher mean score means a higher quality of the overall social network, which is significant for accomplishing one's goals.

The third measure is the highest prestige of network resources. It is evaluated with the highest prestige score among all the people a survey participant knew via participating in an activity. This measure assumes that the best resources are owned within positions with the highest prestige and thus focuses on the upper reachability of a social network [49]. Upper reachability can be an index of richness of social capital, which refers to the estimated high point among the ego social ties in the hierarchical system of the society $[33,50]$. The fourth measure is range in occupational prestige of network resources, which refers to the 
difference between the highest and lowest occupational prestige scores and is connected to having more diverse social network resources [41].

The fifth measure is a social class typologies measure whereby occupations are classified into categories [51] and involve unequal relations between people and their economic or human capital resources which exist among different classes. There may be homogeneous resources within each class but heterogeneous resources between classes. The social-class-based measures examine network resources by counting how many accessed occupations there are in each of the class categories [45,52]. This measure emphasizes qualitative distinctions between different types of network resources rather than quantitative resources (e.g., "more or less" or "better or worse") [41].

In addition to the five position generator measures, sometimes the survey may include questions about the relationships of the contacts to the respondents, such as spouses, parents, colleagues, friends, etc. [33]. As such, further information is obtained about each respondent for each tie type, and the ego's access to social resources via his/her link to positions through specific social relations is evaluated [33,41,45]. The social relations can be calculated by counting the number of occupations linking to those relations [45].

Position generators also ask questions about how close the respondent is to the accessed occupations [9]. This measures the tie strength of the contacts to the respondent [33]. Granovetter [36] defined tie strength as the emotional intensity, intimacy, reciprocity, and temporal duration, which collectively characterize actors' relationships. By evaluating tie strength, it is possible to identify the types of resources that are accessed and the likelihood that those resources will be mobilized [38]. There are two ways of measuring tie strength. One is "closeness," which is preferable, while the other is that the social role that characterizes the tie could be taken as a general proxy for tie strength [38]. An argument regarding the relationships between strong and weak ties of social capital and its outcomes has been noted by previous researchers [49,53]. Some assert that weak ties would better facilitate outcomes (e.g., health) because people can reach a wider scope of social network resources [36], while some believe that strong ties would be better because they are actually helpful for people in need [54]. Based on this argument, the current study was partly designed to examine whether NSC emerging from either strong ties or weak ties can influence sport participation.

\subsection{Social Networks and Sport Participation}

The sport participation literature $[4,26,55-58]$ suggests the contribution of sport participation to establishing social capital. Social capital, such as existing social ties, was found to be a key resource in the initiation and maintenance of running [59], while studies outside the sport field observed that NSC impacted participation behavior (e.g., the more diverse friendship networks are, the less the participation in gardening which needs established friendships.) [35]. To date, only a few studies have adopted the social network theory perspective for examining associations between sport participation and social capital. For example, Legh-Jones and Moore [16] adopted three measures of reachability, diversity, and range to capture social capital and its associations with physical activity, finding that adults with greater network diversity are more likely to be physically active. Widdop et al. [15] used social class and network volume to measure social capital and its influences on sport participation. They found that socioeconomic profile, social class, and the strength and types of ties are associated with levels of sport participation.

A growing body of literature shows that the potentiality of NSC can promote sport participation and reduce physical inactivity among populations. However, only some of the NSC measures were used in Western cultures only (i.e., the United Kingdom and Canada). Thus, using adequate measures of NSC to explore a different cultural context can extend the discussion of sport and social capital from Bourdieu [12], Coleman [13], and Putnam's [10] notion of distinction toward Lin's [19] network resources of social capital.

Based on the literature review and research gaps identified, we set out to determine the extent to which sport participation is likely to be associated with different types of social 
networks. One new attempt of this study is to explore how different types of networks facilitate access to extensity and upper reachability of social capital. We therefore address the following research questions:

RQ1: How do social relations (i.e., kin ties, work ties, friends, and other ties), tie strength (i.e., weak and strong ties), and social class influence accessing extensity and upper reachability of social capital in the running participation context?

RQ2: How do different types of NSC in terms of their extensity, upper reachability, social class, social relations, and tie strength influence sport participation of running exercise participants?

\section{Method}

\subsection{Participants}

Using snowball sampling, we obtained 373 valid responses from 400 respondents across Northern (41.6\%), Central (16.8\%) and Southern (41.6\%) Taiwan. We first targeted running group or club members in each area and then reached for wider samples via connections. Using this sampling method, we efficiently recruited participants better fit for the research purpose. The mean prior number of running events completed by these respondents was 5.79 , and $66.2 \%$ had run marathons, $64.6 \%$ had run half-marathons, $40.5 \%$ had run $10-\mathrm{km}$ races, $31.6 \%$ had run $5-\mathrm{km}$ races, and $57.1 \%$ had run other distances. Among them, $43.4 \%$ belonged to either a running club or a running group. The respondents were $70.1 \%$ male and $29.9 \%$ female, with an average age of 35.93 . The gender proportion obtained in this study approaches that of an investigation (68\% vs. $32 \%$ in $2016 ; 60 \%$ vs. $40 \%$ in 2017) from a professional running organization in Taiwan [60]. Most respondents were not married (58.7\%), had a university or postgraduate education $(83.3 \%)$, were employed $(48.1 \%)$, and had a monthly income of less than TWD $60,000(74.3 \%)$.

\subsection{Measurement}

The survey was conducted in Taiwan. The questionnaires were translated by two bilingual team members from English into traditional Chinese and then back-translated into English to ensure content validity [61]. Two experts in sport management were invited to review the questionnaires which were modified accordingly to ensure face validity. The measures used were as follows.

Sport participation. Sport participation was measured with frequency of participating in running events in the past 12 months (i.e., $1=1$ time, $2=2$ times, $3=3$ times, $4=4$ times, $5=5$ times, $6=6$ times, $7=7$ times and above), frequency of running per week (i.e., $1=1$ day, $2=2$ days, $3=3$ days, $4=4$ days, $5=5$ days, $6=6$ days, and $7=7$ days), and hours spent running per week (i.e., $1=0-1 \mathrm{~h}, 2=1.01-2 \mathrm{~h}, 3=2.01-3 \mathrm{~h}, 4=3.01-4 \mathrm{~h}, 5=4.01-5 \mathrm{~h}$, $6=5.01-6 \mathrm{~h}$, and $7=6.01 \mathrm{~h}$ and above) [62]. Sport participation was analyzed by averaging the three items.

Network Social Capital. The position generators measurement [20] was used to assess NSC. Respondents were asked whether because of participating in running activities they knew somebody with an occupation from a list of 20 occupations based on the Standard International Occupational Prestige Scale (SIOPS) (see Table 1) [33]. The 20 occupations were assigned occupational prestige values based on SIOPS. The range of the prestige score can be from 20 to 85. A series of questions followed, including "What is your relationship with this person?" and "How close are you with this person?" (5-point Likert scale, from $1=$ not at all close to $5=$ very close) (the tie strength variable was categorized into weak and strong ties using a median split; the weak tie group was the reference category and was therefore treated as a dummy variable). These questions were designed to probe patterns of social relations and tie strength among respondents. Based on SIOPS, the collected data were used to assess social capital in four ways. First, we calculated the volume of social capital [21] which we operationalized as the extensity indicator of the position generator [30] by counting the number of occupations accessed by the respondents. Second, we calculated the upper reachability indicator by adopting the prestige score of the highest 
position accessed [30]. Third, we took the type of occupations into account by averaging occupational prestige values of the accessed occupations. Fourth, the occupations were categorized into three classes of social capital based on Goldthorpe's [63] class scheme: the higher service class (e.g., physicians, lawyers, owners of large factories), the intermediate class (e.g., high school teachers, reporters, nurses, managers of large factories/firms), and working class (e.g., police, electricians, truck drivers) (see Table 1). We measured the social class typology by counting the number of occupations accessed in different social classes [41]. To examine the effects of social relations, we distinguished between occupations regarding social relations to spouse, parents/children, kin ties, colleagues (boss/subordinate), and friends (classmate/friend/online friend) [33]. Social relations were measured by counting the number of occupations linking to the social relations. This linking was observed because participants provided the people they knew via participating in running exercise, along with their occupations and the types of relations the participants had with them. Notably, the measurement of range was not adopted due to the issue of multicollinearity.

Profile as a runner. To better understand the runners' backgrounds, respondents were asked to answer the following question: Do you currently belong to a running club or running group? Gender, age, and educational attainment were also included and treated as control variables [15].

Table 1. Prestige scores and social class position in the position generator.

\begin{tabular}{ccc}
\hline Occupation & SIOPS & Social Position $^{\text {a }}$ \\
\hline Legislators (member of parliament, member of local council) & 85 & Higher service class \\
University professor & 78 & Higher service class \\
Medical doctor & 78 & Higher service class \\
Lawyer & 73 & Higher service class \\
Large business owner (25 + employees) & 70 & Higher service class \\
Manager of large firm/factory & 63 & Higher service class \\
Local government officials & 63 & Higher service class \\
Teacher (primary and secondary education) & 60 & Intermediate class \\
Nurse & 54 & Intermediate class \\
Electrical engineer & 65 & Intermediate class \\
Journalist & 58 & Intermediate class \\
Owner of small factory/firm & 52 & Intermediate class \\
Police officers & 40 & Working class \\
Agricultural and fishery workers & 38 & Working class \\
Plant and machine operators and assemblers & 34 & Working class \\
Hairdresser, barber, Beauticians & 32 & Working class \\
Taxi driver & 31 & Working class \\
Protective services workers & 30 & Working class \\
Cleaners & 21 & Working class \\
Porters & 20 & Working class \\
\hline
\end{tabular}

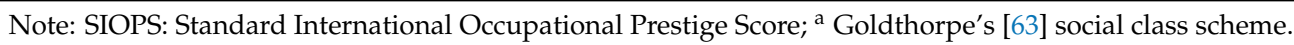

\subsection{Data Analysis}

In order to explore the research questions of the study, hierarchical multiple regression analyses were used to test RQ1 for the effects of social relations (family and kin ties, work related, friend relations), tie strength, and social class (higher service class, intermediate service class, working class) (i.e., independent variables) on accessing social capital in terms of extensity and upper reachability (i.e., dependent variables). To test RQ2, we examined the effects of NSC (independent variables), which was measured with upper reachability and social class along with social relations, tie strength, and social class on sport participation (i.e., dependent variable). Control variables were also used in the second regression model and included gender, age, education attainment, and running club membership. The significance level was set at $\alpha=0.05$. 


\section{Results}

The results showed that the average number of different occupations accessed by the respondents was 5.76, with the mean of the highest occupational prestige at 49.7 and with an average occupational prestige score of 40.52. Respondents had an average of 2.12 occupations accessed from the higher service class, 1.80 from the intermediate class, and 1.89 from the working class. An average number of 1.64 occupations accessed by respondents were family and kin tie relations, and 3.12 were friend relations, while 1.00 occupation was work-related relations. In addition, $76.9 \%$ of respondents had weak ties and $23.1 \%$ had strong ties with people they knew via involvement in running activities. Around $43 \%$ belonged to a running club or group.

The sport participation construct had a mean score of $4.50(S D=3.86)$. To examine normality, the Skewness and Kurtosis values of the results were reported. The absolute values of Skewness and Kurtosis were all acceptable for all variables, with the largest values of Skewness being 1.98 (below 2) and Kurtosis being 5.64 (below 7) [64]. Multicollinearity was examined with tolerance and the variance inflation factor (VIF). The results showed that the lowest value of tolerance was 0.95 (above 0.2 ) and the highest value was 1.05 (less than 4) [65]. This confirmed that there was no occurrence of multicollinearity.

Table 2 presents the results of the regression analyses of social relations, tie strength, and social class on volume of social capital and upper reachability. Model 1 shows that family and kin ties $(\beta=0.35, p<0.001)$, work-related ties $(\beta=0.15, p<0.001)$, and friend relations $(\beta=0.55, p<0.001$ ) have a significant effect on social capital volume when involved in running exercise. However, tie strength $(\beta=0.01, p>0.05)$, higher service class $(\beta=0.01, p>0.05)$, intermediate service class $(\beta=0.01, p>0.05)$, and working class $(\beta=0.02$, $p>0.05$ ) did not have a significant effect on social capital volume. The model as a whole explained $48.6 \%$ of the variance in extensity of social capital.

Model 2 shows that family and kin ties $(\beta=0.17, p<0.001)$, work-related ties $(\beta=0.15$, $p<0.001)$, friend relations $(\beta=0.39, p<0.001)$, tie strength $(\beta=0.11, p<0.01)$, intermediate class $(\beta=0.32, p<0.001)$, and working class $(\beta=-0.15, p<0.01)$ are determinants of obtaining the upper reachability of social capital when involved in running exercise. Nonetheless, higher service class $(\beta=0.10, p>0.05)$ does not have a significant effect on upper reachability of social capital. The model as a whole explained $51.1 \%$ of the variance in upper reachability of social capital.

Table 2. Multiple regression of extensity of social capital and upper reachability on social relations, tie strength, and social class $(\mathrm{n}=373)$.

\begin{tabular}{ccc}
\hline Variables & Model 1 & Model 2 ${ }^{\mathbf{b}}$ \\
\hline Social relations & & \\
Family and kin tie relations & $0.35^{* * *}$ & $0.17^{* * *}$ \\
Work based relations & $0.15^{* * *}$ & $0.15^{* * *}$ \\
Friend relations & $0.55^{* * *}$ & $0.39^{* * *}$ \\
Tie strength (R.G. = weak tie) & 0.01 & $0.11^{* *}$ \\
Social class & & 0.10 \\
Higher service class & 0.01 & $0.32^{* * *}$ \\
Intermediate class & 0.01 & $-0.15^{* *}$ \\
Working class & 0.02 & $51.1 \%$ \\
Adjust R2 & $48.6^{*}$ & \\
\hline
\end{tabular}

Notes: ${ }^{* *} p<0.01, * * * p<0.001{ }^{\text {a }}$ model of extensity of social capital; ${ }^{\mathrm{b}}$ model of upper reachability; R.G. = reference group.

Table 3 presents the results of the hierarchical regression analyses of NSC on sport participation. The extensity of social capital (tolerance value $=0.01, \mathrm{VIF}=71.09$ ) and the average occupational prestige score (tolerance value $=0.18, \mathrm{VIF}=5.47$ ) were excluded from the data analyses due to multicollinearity [63]. Model 1 (which examined the influence of the control variables on sport participation) revealed that age $(\beta=0.31, p<0.001)$ and running club membership $(\beta=0.19, p<0.001)$ had a significant effect on sport participation. 
However, gender $(\beta=0.01, p>0.05)$ and education attainment did not. Model 2 shows that after controlling for gender, age, education attainment, and running club membership, individuals who had strong ties with the people known via running exercise were more likely to be active in running exercise compared to those with weak ties $(\beta=0.17, p<0.01$ ) (dummy variable). However, family and kin tie relations $(\beta=-0.06, p>0.05)$, work-related ties $(\beta=-0.07, p>0.05)$, and friend relations $(\beta=0.10, p>0.05)$, upper reachability $(\beta=0.10$, $p>0.05)$, higher service class $(\beta=0.10, p>0.05)$, intermediate class $(\beta=-0.06, p>0.05)$, and working class $(\beta=-0.01, p>0.05)$ did not have significant effects on sport participation. The model as a whole explained $25 \%$ of the variance in sport participation.

Table 3. Linear regression of network social capital on sport participation $(n=373)$.

\begin{tabular}{|c|c|c|c|c|}
\hline & \multicolumn{2}{|c|}{ Model 1} & \multicolumn{2}{|c|}{ Model 2} \\
\hline & $\beta$ & $\mathrm{t}$ & $\beta$ & $\mathrm{t}$ \\
\hline Genger (R.G. = Female) & 0.01 & 0.26 & 0.51 & 0.61 \\
\hline Age & 0.31 & $5.40^{* * *}$ & 0.27 & $4.82^{* * *}$ \\
\hline \multicolumn{5}{|l|}{ Education (R.G. = Vocational school and under) } \\
\hline Undergraduate & 0.02 & 0.22 & 0.01 & 0.05 \\
\hline Master and above & 0.02 & 0.33 & -0.01 & -0.20 \\
\hline Membership in a running club (R.G = No) & 0.19 & $3.60^{* * *}$ & 0.1 & 1.81 \\
\hline \multicolumn{5}{|l|}{ Network social capital } \\
\hline Family and kin tie relations & & & -0.06 & -1.07 \\
\hline Work based relations & & & -0.07 & -1.36 \\
\hline Friend relations & & & 0.10 & 1.09 \\
\hline Upper reachability & & & 0.10 & 1.48 \\
\hline Tie strength (R.G. = weak tie) & & & 0.17 & $3.48^{* *}$ \\
\hline Higher service class & & & 0.10 & 1.10 \\
\hline Intermediate class & & & -0.06 & -0.59 \\
\hline Working class & & & -0.01 & -0.15 \\
\hline $\mathrm{R} 2$ & \multicolumn{2}{|c|}{0.17} & \multicolumn{2}{|c|}{0.25} \\
\hline Adjust R2 & \multicolumn{2}{|c|}{0.16} & \multicolumn{2}{|c|}{0.22} \\
\hline $\mathrm{F}$ & \multicolumn{2}{|c|}{$14.46^{* * *}$} & \multicolumn{2}{|c|}{$8.88^{* * *}$} \\
\hline
\end{tabular}

Note: Dependent variable $=$ sport participation; ${ }^{* *} p<0.01 ;{ }^{* * *} p<0.001$.

\section{Discussion}

The purpose of the study was to explore how the position generator scale influences social capital and sport participation outcomes and therefore contributed to the sport literature in two ways. First, this study contributes to a better understanding of NSC theory by evidencing that specific social relations, tie strength, and heterogeneity of network resources (social classes) can assist a running exercise participant in accessing more diversified social networks and networks with higher prestige or status. Second, to assess the influence of network social capital on personal participation in running exercise, this study examined the association among extensity, upper reachability, social class, social relations, and tie strength and found that strong ties with people in the running community (homogeneity) influence engagement frequency in running. Taken together, this paper addresses two important research questions as discussed below.

With regard to the first research question, the findings indicated that running exercise participants established their social networks in running participation contexts with mostly friend relations, followed by family and kin tie relations, and working relations. This is similar to Lin et al. [33] who found that Taiwanese people greatly rely on friend relations to have diverse networks in different occupations, followed by work-based relations and kin ties. Furthermore, the results showed that the tie strength had no significant influence on the volume of social capital, which is inconsistent with Lin et al. [33], who found that both strong and weak ties are positively associated with volume of social capital. The differences may be due to different study contexts as Lin et al. [33] targeted the general population, whereas the current study targeted running activity participants. Our findings indicated that social connections from different classes have no significant influence on 
obtaining diverse networks. Along with the findings associated with social relations, this suggests that participants in running activities rely on social relations rather than social classes to diversify their social networks.

Furthermore, the findings indicated that running exercise participants can reach people with higher social status via diverse social relations (i.e., friends, family and kin ties, and colleagues) in running participation contexts. This is in line with Lin et al. [33], who found that Taiwanese people use diverse social relations to obtain social capital richness. In addition, our findings indicated that participants in running exercise rely on strong ties to obtain better social capital, implying that being involved in running activities and frequently interacting with members within and outside running groups can be a pathway to contacting the higher social circles in society and thus better network resources. The results also indicated that social connections from different classes differently impact accessibility of upper reachability of social capital. Notably, we found that having access to higher service class occupations is not significantly associated with the upper reachability of social capital and having access to more intermediate class occupations is significantly and positively associated with upper reachability, whereas having access to working class occupations is significantly negatively associated with upper reachability. Our results suggest that people with access to more intermediate class occupations also have access to higher service class occupations. In addition, the negative association between working class and upper reachability could be explained by the reason that working class people may have less access to better social capital. This may be in line with $\mathrm{Li}$, Savage, and Warde [66] and Verhaeghe and Li [41], implying the strong extent of homogeneous class relationships in running exercise and in society.

Regarding the second research question, our results showed that running exercise participants who had more frequent contact with people they know through being involved in running activities would likely have a higher level of sport participation. This is consistent with Lin et al.'s [54] and Lin's [19] social capital theory which states that strong ties are good for expressive goals, whereas it opposes Granovetter's [36] view that weak ties would be better for accessing a more diverse range of social network resources. The results are similar to Wiltshire and Stevinson's [59] findings, suggesting that running exercise participants may initiate their running exercise based on existing social ties, then draw on the acquired social capital developed during intensive daily interactions within running communities to accumulate cultural capital (e.g., information relating to injury management, performance, and health), which assists the maintenance of participation in running. Notably, the influence of tie strength on sport participation should also take age into account, with older running exercise participants being more active in running events and daily practice. It is reasonable to expect that when people are committed to a sports club or a group for a certain period of time, the social networks developed will drive continuous participation. In addition, the cultural context (i.e., a collective society) where this study took place may have accentuated higher participation intentions given the influence of peers in Eastern cultures and the importance of relationships [67]. However, recent research [68] suggests that consumers within Chinese cultures may feature some idiocentric behaviors in various servicescapes, which could influence social capital development differently. Given that running may be at times an individualistic sport, it would be interesting to compare Eastern and Western cultures in terms of their social capital gains through their participation in running events.

Without considering the influence of NSC factors, participants who belong to a running club may be more likely to participate in running activities than those who are not. Joining running clubs could be seen as a kind of social participation [16], indirectly increasing individuals' access to information regarding training skills and informal social interactions which encourage more frequent participation in running activities. This finding may imply a sense of belonging or attachment to a group, which can have an important bearing on people's sport participation behaviors [15]. The cultural context can also enable these tendencies given the influence of Confucian values of relationships and faces [69]. 


\subsection{Practical Implications}

This study found that participating in running exercise facilitates access to wider varieties of people with different occupations. Specifically, to improve social capital volume, maintaining relationships with family members, relatives, working colleagues, and friends is viable for achieving a higher volume of social capital. From a practical perspective, runners should aim to have wider social networks from different occupations, be involved in running activities, participate in running events, and practice with other runners.

Findings suggested different patterns of social relations, and the strong ties with people who participate in running activities exert significant effects on accessing better social capital. The results further revealed that participants in running exercise highly relied on friend relations to access better social capital, followed by family and kin tie relations, and work ties. Thus, running exercise is a platform for building up diverse social connections which can assist in gaining better social capital. As obtaining better social capital is also determined by higher degrees of closeness, creating frequent interaction during involvement in running activities is advisable. Notably, different socioeconomic groups vary in terms of obtaining better social capital. Particularly, participants who know working class people are disadvantaged in gaining better social capital. Thus, it is advisable that overarching initiatives or programs aiming to reduce inequalities should be put in place by running club organizers.

Our study's findings about NSC relating to social relations, upper reachability, and social classes did not show an association with sport participation. It may reflect the fact that running exercise is a civic sport [3] where people's commitment to continuous participation relies much more on interactions during practice or training than on their socioeconomic status (gender, education, classes) and different types of relationships. In addition, running is accessible to everyone, regardless of class. Thus, public sport authorities and the private sector should seriously consider investing in running clubs where they can offer scheduled daily training courses (e.g., skill training, injury prevention, etc.), as well as informal social activities (e.g., interaction within and between running clubs) to further boost participation intentions and improve overall health. These are some strategies relating to NSC addressed to encourage continuous participation in sport (e.g., running).

\subsection{Limitations and Future Study Suggestions}

This study is based on Lin's [9] NSC theory but only explored expressive returns as outcomes. Further examination of the influences of sport participation and social capital on instrumental returns (e.g., wealth, power, reputation) may offer fuller insights. We examined NSC and sport participation by testing a Taiwanese sample in a specific context and found that NSC was partly supported. However, social capital is contextspecific in terms of sociocultural settings and the subjects studied [56]. To fully understand the extent to which the theory is generalized, future research is encouraged to test it in different countries, cultures, types of sport (e.g., team vs. non-team sports) and sport activities (e.g., tennis, swimming, football, etc.). Importantly, measurements of position generators were adopted in the current study but have scarcely been used in the sport field. Future sport studies could use the position generators to improve the comparability and generalization in this line of research. The current study examining NSC targeted only individuals. However, sport scholars are encouraged to target multilevel interventions to better understand how social capital outcomes (e.g., health) are simultaneously affected by both the individual and community levels [14].

Author Contributions: Conceptualization, S.-C.M. and K.K.; methodology, S.-C.M. and K.K.; formal analysis, S.-C.M.; data curation, S.-C.M.; writing-original draft preparation, S.-C.M. and K.K.; writing-review and editing, S.-C.M. and K.K. All authors have read and agreed to the published version of the manuscript.

Funding: This research was funded by the Ministry of Science and Technology (MOST), Taiwan, MOST 107-2410-H-006-099-MY2. 
Institutional Review Board Statement: The study was conducted according to the guidelines of the Declaration of Helsinki, and approved by the National Cheng Kung University Human Research Ethics Committee (Approval No.: NCKU HREC-E-107-158-2; date of approval: 8 August 2018).

Informed Consent Statement: Informed consent was obtained from all subjects involved in the study. Data Availability Statement: Not applicable.

Conflicts of Interest: The authors declare no conflict of interest.

\section{References}

1. Kumar, H.; Manoli, A.E.; Hodgkinson, I.R.; Downward, P. Sport participation: From policy, through facilities, to users' health, well-being, and social capital. Sport Manag. Rev. 2018, 21, 549-562. [CrossRef]

2. Downward, P.; Hallmann, K.; Rasciute, S. Exploring the interrelationship between sport, health and social outcomes in the UK: Implications for health policy. Eur. J. Public Health 2018, 28, 99-104. [CrossRef] [PubMed]

3. Ma, S.C.; Kaplanidou, K. Effects of event service quality on the quality of life and behavioral intentions of recreational runners. Leis. Sci. 2018, 1-21. [CrossRef]

4. Sherry, E.; Karg, A.; O'May, F. Social capital and sport events: Spectator attitudinal change and the Homeless World Cup. Sport Soc. 2011, 14, 111-125. [CrossRef]

5. Taylor, P.; Davies, L.; Wells, P.; Gilbertson, J.; Tayleur, W. A Review of the Social Impacts of Culture and Sport; Department for Culture, Media and Sport: London, UK, 2015.

6. Sobel, J. Can we trust social capital? J. Econ. Lit. 2002, 40, 139-154. [CrossRef]

7. Zhou, R.; Kaplanidou, K. Building social capital from sport event participation: An exploration of the social impacts of participatory sport events on the community. Sport Manag. Rev. 2018, 21, 491-503. [CrossRef]

8. Mastromartino, B.; Wang, J.J.; Suggs, D.W.; Hollenbeck, C.R.; Zhang, J.J. Dimensions of sense of membership in a sport fan community: Factors, outcomes, and social capital implications. Commun. Sport 2020. [CrossRef]

9. Lin, N. Building a network theory of social capital. Connections 1999, 22, 28-51.

10. Putnam, R.D. Bowling alone: America's declining social capital. J. Democr. 1995, 6, 65-78. [CrossRef]

11. Delhey, J.; Newton, K. Who trusts? The origins of social trust in seven societies. Eur. Soc. 2003, 5, 93-137. [CrossRef]

12. Bourdieu, P. The forms of capital. In Handbook of Theory of Research for the Sociology of Education; Richardson, J.E., Ed.; Greenwood Press: New York, NY, USA, 1986; pp. 241-258.

13. Coleman, J. Social capital in the creation of human capital. Am. J. Sociol. 1988, 94, S95-S120. [CrossRef]

14. Villalonga-Olives, E.; Wind, T.R.; Kawachi, I. Social capital interventions in public health: A systematic review. Soc. Sci. Med. 2018, 212, 203-218. [CrossRef]

15. Widdop, P.; Cutts, D.; Jarvie, G. Omnivorousness in sport: The importance of social capital and networks. Int. Rev. Sociol. Sport 2016, 51, 596-616. [CrossRef]

16. Legh-Jones, H.; Moore, S. Network social capital, social participation, and physical inactivity in an urban adult population. Soc. Sci. Med. 2012, 74, 1362-1367. [CrossRef] [PubMed]

17. Sports Administration, Ministry of Education. Physcial Education (Sport) Statistics. 2021. Available online: https://www.sa.gov. tw /ebook/List?id=12\&n=493 (accessed on 30 October 2021).

18. Running Biji. Running Investigation-What Do Runners Look Like? Are They Young Guys or the Middle-Aged? 2021. Available online: https: / / running.biji.co/index.php?q=news\&act=info\&id=105390\&subtitle= (accessed on 29 October 2021).

19. Lin, N. Social Capital: A Theory of Structure and Action; Cambridge University Press: London, UK, 2001.

20. Lin, N. Building a network theory of social capital. In Social Capital: Theory and Research; Lin, N., Cook, K., Burt, R.S., Eds.; Aldine de Gruyter: New York, NY, USA, 2001; pp. 3-30.

21. Van der Gaag, M. Measurement of Individual Social Capital. Ph.D. Thesis, University of Groningen, Groningen, The Netherlands, 2005.

22. Bourdieu, P. Distinction: A Social Critique of the Judgment of Taste; Harvard University Press: Cambridge, UK, 1984.

23. Tomlinson, A. Pierre Bourdieu and the sociological study of sport: Habitus, capital and field. In Sport and Modern Social Theorists; Giulianotti, R., Ed.; Palgrave Macmillan: New York, NY, USA, 2004; pp. 161-172.

24. Siisiäinen, M. Two concepts of social capital: Bourdieu vs. Putnam. In Proceedings of the ISTR Fourth International Conference, Dublin, Ireland, 5-8 July 2000.

25. Tzanakis, M. Social capital in Bourdieu's, Coleman's and Putnam's theory: Empirical evidence and emergent measurement issues. Educate 2013, 13, 2-23.

26. Welty Peachey, J.; Cohen, A.; Borland, J.; Lyras, A. Building social capital: Examining the impact of Street Soccer USA on its volunteers. Int. Rev. Sociol. Sport 2013, 48, 20-37. [CrossRef]

27. Putnam, R.D. Bowling Alone: The Collapse and Revival of American Community; Simon \& Schuster: New York, NY, USA, 2000.

28. Lee, S.P.; Cornwell, T.B.; Babiak, K. Developing an instrument to measure the social impact of sport: Social capital, collective identities, health literacy, well-being and human capital. J. Sport Manag. 2013, 27, 24-42. [CrossRef]

29. Pawar, M. "Social" "capital"? Soc. Sci. J. 2006, 43, 211-226. [CrossRef] 
30. Lin, N.; Fu, Y.C.; Hsung, R.M. The position generator: Measurement techniques for investigations of social capital. In Social Capital: Theory and Research; Lin, N., Cook, K., Burt, R.S., Eds.; Aldine de Gruyter: New York, NY, USA, 2001 ; pp. 57-82.

31. Wasserman, S.; Faust, K. Social Network Analysis: Methods and Applications; Cambridge University Press: Cambridge, UK, 1994.

32. Borgatti, S.P.; Jones, C.; Everett, M.G. Network measures of social capital. Connections 1998, 21, 27-36.

33. Lin, N.; Chen, C.J.; Fu, Y.C. Patterns and effects of social relations: A comparison of Taiwan, the United States and China. Taiwan J. Sociol. 2010, 45, 117-162.

34. Lizardo, O. How cultural tastes shape personal network. Am. Sociol. Rev. 2006, 71, 778-807. [CrossRef]

35. Warde, A.; Tampubolon, G. Social capital, networks and leisure consumption. Sociol. Rev. 2002, 50, 155-180. [CrossRef]

36. Granovetter, M. The strength of weak ties. Am. J. Sociol. 1973, 78, 1360-1380. [CrossRef]

37. Burt, R.S. Structural Holes: The Social Structure of Composition; Harvard University Press: Cambridge, UK, 1992.

38. Moore, S.; Kawachi, I. Twenty years of social capital and health research: A glossary. J. Epidemiol. Community Health 2017, 71, 513-517. [CrossRef] [PubMed]

39. Hawe, P.; Webster, C.; Shiell, A. A glossary of terms for navigating the field of social network analysis. J. Epidemiol. Community Health 2004, 58, 971-975. [CrossRef] [PubMed]

40. Vang der Gaag, M.; Snijders, T.A.B. The resource generator: Social capital quantification with concrete items. Soc. Netw. 2005, 27, 1-29. [CrossRef]

41. Verhaeghe, P.P.; Li, Y. The position generator approach to social capital research: Measurements and results. In Handbook of Research Methods and Applications in Social Capital; Li, Y., Ed.; Edward Elgar: Cheltenham, UK, 2015; pp. $166-186$.

42. Ganzeboom, H.B.G.; Treiman, D.J. Internationally comparable measures of occupational status for the 1988 International Standard Classification of Occupations. Soc. Sci. Res. 1996, 25, 201-239. [CrossRef]

43. Treiman, D.J. Occupational Prestige in Comparative Perspective; Academic Press: New York, NY, USA, 1977.

44. Lin, N. Social resources and instrumental action. In Social Structure and Network Analysis; Marsden, P.V., Lin, N., Eds.; Sage: Beverly Hills, CA, USA, 1982; pp. 131-145.

45. Lin, N.; Dumin, M. Access to occupations through social ties. Soc. Netw. 1986, 8, 365-385. [CrossRef]

46. McDonald, S.; Lin, N.; Ao, D. Networks of opportunity: Gender, race, and job leads. Soc. Probl. 2009, 56, 385-402. [CrossRef]

47. Erickson, B.H. Why some occupations are better known than others. In Social Capital: An International Research Program; Lin, N., Erickson, B.H., Eds.; Oxford University Press: Oxford, UK, 2008; pp. 331-341.

48. Miyata, K.; Ikeda, K.; Kobayashi, T. The Internet, social capital, civic engagement, and gender in Japan. In Social Capital: An International Research Program; Lin, N., Erickson, B.H., Eds.; Oxford University Press: Oxford, UK, 2008; pp. $206-233$.

49. Verhaeghe, P.P.; Van de Putte, B.; Roose, H. Reliability of position generator measures across different occupational lists: A parallel test experiment. Field Methods 2012, 25, 238-261. [CrossRef]

50. Lin, N.; Fu, Y.C.; Chen, C.J.J. Structuring social capital: Social, cultural and institutional dimensions. In Proceedings of the International Conference on Social Capital, Taipei, Taiwan, 29-30 May 2008.

51. Ganzeboom, H.B.G.; De Graaf, P.M.; Treiman, D.J. A standard international socio-economic index of occupational status. Soc. Sci. Res. 1992, 21, 1-56. [CrossRef]

52. Enns, S.; Malinick, T.; Matthews, R. It's not only who you know, it's also where they are. In Social Capital: An International Research Program; Lin, N., Erickson, B., Eds.; University Press: Oxford, UK, 2008; pp. 255-281.

53. Maness, M. A theory of strong ties, weak ties, and activity behavior: Leisure activity variety and frequency. Transp. Res. Rec. 2017, 2665, 30-39. [CrossRef]

54. Lin, N.; Ensel, W.; Vaughn, J. Social resources and strength of ties: Structural factors in occupational attainment. Am. Sociol. Rev. 1981, 46, 393-405. [CrossRef]

55. Mackellar, J.; Jamieson, N. Assessing the contribution of a major cycle race to host communities in South Australia. Leis. Stud. 2015, 34, 547-565. [CrossRef]

56. Tonts, M. Competitive sport and social capital in rural Australia. J. Rural. Stud. 2005, 21, 137-149. [CrossRef]

57. Welty Peachey, J.; Borland, J.; Lobpries, J.; Cohen, A. Managing impact: Leveraging scared spaces and community celebration to maximize social capital at a sport-for-development event. Sport Manag. Rev. 2015, 18, 86-98. [CrossRef]

58. Yamamura, E. Effect of professional sports teams on social capital formation: Comparison between football and baseball in Japan. In The Sports Business in the Pacific Rim, Sports Economics, Management and Policy; Lee, Y.H., Fort, R., Eds.; Springer International Publishing: Berlin/Heidelberg, Germany, 2015; pp. 355-367.

59. Wiltshire, G.; Stevinson, C. Exploring the role of social capital in community-based physical activity: Qualitative insights from parkrun. Qual. Res. Sport Exerc. Health 2018, 10, 47-62. [CrossRef]

60. Running Biji. 2017 Running Investigation-Running Experience and Habit. 2018. Available online: https://running.biji.co/index. php?q=news\&act $=$ info\&id $=97867 \&$ subtitle $=($ accessed on 20 June 2021).

61. Brislin, R.W. Back-translation for cross-cultural research. J. Cross-Cult. Psychol. 1970, 1, 185-216. [CrossRef]

62. Newman, D.B.; Tay, L.; Diener, E. Leisure and subjective well-being: A model of psychological mechanisms as mediating factors. J. Happiness Stud. 2014, 15, 555-578. [CrossRef]

63. Goldthorpe, J.H. Social Mobility and Class Structure in Modern Britain; Clarendon Press: Oxford, UK, 1987.

64. Kline, R.B. Principles and Practice of Structural Equation Modeling, 2nd ed.; The Guilford Press: New York, NY, USA, 2005. 
65. Hair, J.F.; Black, W.C.; Babin, B.J.; Anderson, R.E. Multivariate Data Analysis, 7th ed.; Pearson Prentice Hall: Upper Saddle River, NJ, USA, 2010.

66. Li, Y.; Savage, M.; Warde, A. Social mobility and social capital in contemporary Britain. Br. J. Sociol. 2008, 59, 391-411. [CrossRef]

67. Hofstede, G. Culture and Organizations Software of the Mind; McGraw-Hill: New York, NY, USA, 1997.

68. Warden, C.A.; Huang, S.C.-T.; Yen, W.-H.; Chen, J.F. The Tao of consumption: Private self in a collective culture. J. Serv. Theory Pract. 2021, 31, 756-782. [CrossRef]

69. Fu, X.; Cai, L.; Lehto, X. Framing Chinese tourist motivations through the lenses of confucianism. J. Travel Tour. Mark. 2017, 34, 149-170. [CrossRef] 